\title{
¿Quién es quién?
}

\section{Who is who?}

\author{
Jesús C. Briones-Garduño*
}

Servicio de Ginecología y Obstetricia, Hospital General de México Dr. Eduardo Liceaga; Especialidad de Medicina Crítica en Obstetricia, Facultad de Medicina, Universidad Nacional Autónoma de México. Ciudad de México, México

Quien es un pronombre relativo, que se emplea en referencia a personas. Quién es un pronombre que puede ser tanto exclamativo como interrogativo. Quien es un monosílabo átono, razón por la cual se escribe sin tilde gráfica. Quién es una palabra tónica, por lo cual lleva una tilde diacrítica.

¿Por qué nos debemos preguntar «quién es quién» en el hospital donde trabajamos, donde nos desarrollamos como médicos y como personas? ¿Qué trascendencia tiene nuestro esfuerzo en lo asistencial, en lo docente, en la investigación y también, ahora, en lo administrativo? Estas preguntas pretenden ser una reflexión en una atmósfera nosocomial allanada por protagonismos pintorescos, en ocasiones colmados de egocentrismo muchas veces magnificado por el burocratismo institucional en cascada y vertebrado a políticas individuales un tanto virtuales y otro tanto reales. La imaginación que se requiere para convertirse en académico implica una disciplina, una metodología y un compromiso no solo personal, sino también social; es una responsabilidad con la comunidad a la que pertenecemos y nos debemos, que nos convierte en un referente con autoridad no solo académica, sino también moral, que se transforma en un liderazgo que trasciende las fronteras del conocimiento en beneficio de nuestros propios pacientes, alumnos, compañeros, amigos y familiares.

A la manera de Giovanni Sartori, "definir no es lo mismo que demostrar; hemos llegado a ser demasiado normativos e incluso demasiado emotivos, demasiado normativos no solo en el sentido de que el deber ser suplanta demasiado al ser, al mundo, como es, sino también en el sentido de que perseguimos objetivos sin instrumentos, sin saber cómo y demasiado emotivos en el sentido de que el sentir trasforma la razón. La solidaridad, está bien; pero no es suficiente».

«Si aceptamos que la salud es esencialmente un concepto social, también condicionado por las características biológicas, pero donde el aspecto social es mucho más importante, las desigualdades de salud que tienen un origen social son injustas e injustificadas porque representan la distribución de los recursos de la sociedad de tal manera que ciertos grupos no disponen de oportunidades o de libertades humanas básicas."

El proceso salud-enfermedad involucra a los individuos en su totalidad y a su entorno; los pacientes no se enferman por fragmentos, de modo que requieren del profesional que los vea en su totalidad.

La sociedad requiere no solo al médico técnicamente competente y experto en procedimientos, sino también a quien sepa comprender a los pacientes, empatizar con ellos y actuar en defensa de su salud ${ }^{1,2}$.

El hospital es el escenario de nuestro quehacer cotidiano, y modula y propicia el potencial para lograr, a través de la competencia, obtener el sitial seleccionado acorde con la trayectoria recorrida, abriendo una brecha en el presente y con visión hacia el futuro. Tal es el caso del Hospital General de México Dr. Eduardo Liceaga, unidad médica emblemática que durante más de un siglo de historia ha permitido el crecimiento de personalidades de la medicina nacional que contribuyen al desarrollo de políticas de salud con impacto en la población usuaria, y en la enseñanza, capacitando a miles de integrantes del equipo de

\author{
Correspondencia: \\ *Jesús C. Briones-Garduño \\ Dr. Balmis, 148 \\ Col. Doctores, Del. Cuauhtémoc \\ C.P. 06726, Ciudad de México, México \\ E-mail: drcarlosbriones@yahoo.com.mx \\ Fecha de recepción: 23-05-2018 \\ Fecha de aceptación: 02-06-2018 \\ DOI: 10.24875/CIRU.M18000062
}

Cir Cir. 2019;87:5-6

Contents available at PubMed www.cirugiaycirujanos.com 
salud, y en el progreso del conocimiento científico-administrativo. Como testimonio tenemos nombres como Abdo Francis, Andrade Cárdenas, Arrollo Yllanes, Athié Gutiérrez, Basurto Kuba, Bernal Sahagún, Bravo Bernabé, Briones Garduño, Buitrón García Figueroa, Carrillo Esper, Carrillo Ruíz, Charúa Guindic, Cicero Sabido, Cuevas Covarrubias, Escotto Velásquez, Fanghanel Salmón, García Irigoyen, González Chávez, González Martínez, Guerrero Avendaño, Gutiérrez Vega, Hernández Carbajal, Hurtado López, Jiménez Ponce, Mendoza Morfin, Navarro Reynoso, Pérez Torres, Soria Fernández, Torres Lobaton, Valdespino Gómez, Vargas Domínguez, Zenteno Alanís, y muchos más.

Cuando nos preguntemos quién es quién, podemos voltear y ver al Hospital General de México Dr. Eduardo Liceaga, "el General de los Hospitales", como menciona el Dr. Navarro Reynoso, el nosocomio con mayor número de académicos de nuestro país, ayer, hoy y mañana. El proyecto del hospital fue aprobado el 22 de noviembre de 1895, y el día 5 de febrero de
1905, siendo Presidente de la República el General José de la Cruz Porfirio Díaz Mori, se inauguraron las instalaciones del Hospital General de México ${ }^{3}$.

«En la naturaleza existen seres que vegetan, otros se manifiestan por una conducta instintiva y los más favorecidos, filosofan."

«En la vida del ser humano existen dos grandes épocas: la fisiológica, en la que se hace alarde de crecimiento y reproducción, y la época filosófica, que nos revela en la intimidad y nos desnuda el alma al punto tal que la muerte significa nada"4.

\section{Bibliografía}

1. Cano Valle F. Prospectiva del sistema de salud en México. En: Cano Valle F, editor. La posición de la Academia ante el Sistema Nacional de Salud. La salud universal, una entelequia. México: Academia Nacional de Medicina de México; 2018.

2. Lifschitz GA, García VJL, Flores MF. La medicina general en México. Documento de postura, Academia Nacional de Medicina. México: Editorial Intersistemas SA de CV; 2015.

3. Briones GJC, Díaz de León PM. Probabilidad y riesgo. Rev Asoc Mex Med Crit y Ter Int. 2007;21:13-4.

4. Briones GJC. Educación, reproducción y valores humanos. Revista de la Facultad de Medicina. 2000;1:18-21. 